J. Clin. Chem. Clin. Biochem.

Vol. 26, 1988, pp. 599-604

(C) 1988 Walter de Gruyter \& Co.

Berlin - New York

\title{
Bioluminescent Monitoring of ATP Release from Human Red Blood Cells Treated with Nonionic Detergent ${ }^{1}$ )
}

\author{
By Tamás Köszegi, Miklós Kellermayer, Ferenc Kövecs and Kázmér Jobst \\ Department of Clinical Chemistry, University Medical School, Pécs, Hungary
}

(Received October 21, 1987/May 2, 1988)

Summary: The adaptation of the firefly luciferin-luciferase system for the detection of ATP in the presence of Triton X 100 or Brij 58 nonionic detergents is described. The method is sensitive, easy to perform and is suitable for the continuous monitoring of the mobilization rate of ATP from Triton X 100- or Brij 58-treated human erythrocytes. A very rapid ATP release was observed after Triton X 100 treatment of the red blood cells while the presence of Brij 58 caused a retarded mobilization of the intracellular ATP. The technique described seems to be applicable to all kinds of cells.

\section{Introduction}

In the last two decades the firefly bioluminescence system has been extensively used for the determination of intracellular ATP concentrations (1-4). Although many different procedures exist for the estimation of cellular ATP, the majority of these tests include two identical steps:

(i) complete extraction of ATP from the cells,

(ii) rapid denaturation of the intracellular ATP degrading enżymes.

The use of denaturing chemicals like trichloroacetic acid, perchloric acid, etc. (5) fulfils both requirements and gives reliable estimates on the total ATP content of a cell, but it does not permit an insight into the association of ATP with intracellular proteins in the living cell. In order to analyse the protein-ATP associations, a promising approach would be to measure continuously the amount of ATP released from permeabilized cells in non-denaturing conditions. The validity of such an approach has already been proved

1) The work was supported by the Hungarian Academy of Sciences, Grant No: OTKA 83, and the Hungarian Academy of Sciences - National Science Foundation, USA Joint Grant No: 30.070/32/86, and the Ministry of Health Grant: ETT $1 / 267$. by the observation that nonionic detergent-induced removal of the lipid membrane of a cell is not immediately followed by the complete release of the intracellular "soluble" components $(6,7)$. Analysis of the release kinetics of $\mathrm{K}^{+}$and proteins in the presence of nonionic detergents has already shown that this technique can provide information on the compartmentation of $\mathrm{K}^{+}$in living cells $(7,8)$.

The purpose of our experiments was to work out a method which is applicable to the investigation of the compartmentation or association of ATP in practically every type of mammalian cell. For the permeabilization of the cells we used Triton X 100 and Brij 58 nonionic detergents. On the basis of our findings we have demonstrated that:

(i) the light emitting reaction is not affected seriously by the presence of nonionic detergents,

(ii) using human red blood cells the detergent induced ATP release kinetics can be followed continuously after the addition of Triton X 100 or Brij 58 to the luciferin-luciferase reagent,

(iii) the striking difference in the release curves between the two nonionic detergents may give fresh insights into the protein-ATP associations in the cell. 


\section{Materials and Methods}

Chemicals

Crystalline firefly luciferase ${ }^{2}$ ), synthetic luciferin and ATP $\cdot \mathrm{Na}_{2}$ salt were from Boehringer, Mannheim, West Germany. Triton $X 100$ was purchased from Serva, Heidelberg, West Germany. Brij 58 was from Sigma, St. Louis. All other reagents were of analytical grade. We worked with freshly prepared tridistilled water throughout the experiments. For the analysis of the intracellular ATP release kinetics, venous blood from healthy donors as well as from randomly selected outdoor patients was used, which had been anticoagulated with EDTA $\cdot \mathrm{Na}_{2}$.

\section{Reagent preparation}

All measurements, dilutions and standard preparations were done with the following buffer solution: $0.1 \mathrm{~mol} / 1$ Tris/acetate, $10 \mathrm{mmol} / \mathrm{l} \mathrm{MgSO}_{4}, 2 \mathrm{mmol} / 1 \mathrm{EDTA} \cdot \mathrm{Na}_{2}, \mathrm{pH} 7.5$. Our ATP reagent contained $7 \mathrm{mg} / 1$ luciferase, $12 \mu \mathrm{mol} / 1$ luciferin in the Tris buffer (end concentration in $1.25 \mathrm{ml}$ of total sample volume). ATP standards were prepared from an $0.1 \mathrm{mmol} / 1$ stock solution dissolved in water in the $0.25 \mathrm{nmol} / \mathrm{l}-25 \mathrm{nmol} / \mathrm{l}$ range. For the acid extraction of intracellular ATP we used $1 \mathrm{~mol} / 1$ perchloric acid and $0.1 \mathrm{~mol} / 1$ Tris/acetate, $20 \mathrm{mmol} / 1$ EDTA $\cdot \mathrm{Na}_{2}, \mathrm{pH}$ 7.7. For the detergent extraction of ATP 10 $\mathrm{g} / \mathrm{l}$ stock solutions of Triton $\mathrm{X} 100$ and Brij 58 were made in the Tris buffer described above.

\section{Instrumentation and calculation of data}

The bioluminescence signal originating from the samples was measured using the photon counting technique. A light tight sample box was constructed which could accommodate rotatable polypropylene cuvettes and the emitted photons were detected by the photomultiplier tube of an SP-8X fluorescence photometer (Applied Photophysics, London, England). The detector was connected to a multichannel analyser (Central Research Institute for Physics, Budapest, Hungary) which was interfaced to a host computer. The multichannel analyser was operated in the multiscaling mode at a 1 second time resolution. In the experiments, where ATP standard solutions were analysed or quantitative data on the intracellular ATP were obtained, the bioluminescence intensity of the samples was measured for 1-2 minutes, the photon counts in the corresponding 60-120 channels averaged, and the standard deviations calculated. The average photon count of a sample was considered as an individual measuring point. The luminescence intensity values in all experiments are given as photon counts per second. Since the coefficient of variation varied between $1 \%$ and $3 \%$ the standard deviations are not indicated in the figures. In those experiments where the actual ATP contents were calculated we used internal ATP standards, and the ATP values were referred to the haematocrit of the blood samples (ATP, mmol/l red cell mass). In the ATP release analyses, the light signal was monitored for 1024 seconds. For long term monitoring and for serial measurements of Brij 58-induced ATP release, we used an LB 9505 luminometer $^{3}$ ) (Laboratorium Prof. Dr. Berthold, Wildbad, Germany). Measurements were performed at $20 \pm 2^{\circ} \mathrm{C}$.

\section{ATP standard curves}

The effect of the nonionic detergents on the light emitting reaction was examined using ATP standard solutions. Light signals were analysed in the absence, and in the presence of 0.8

$\left.{ }^{2}\right)$ Enzymes: Firefly luciferase (Photinus luciferin : ogygen 4-oxidoreductase (EC 1.13.12.7.)).

$\left.{ }^{3}\right)$ A generous gift of the Alexander von Humboldt Foundation. $\mathrm{g} / 1$ Triton $\mathrm{X} 100$ and Brij 58, respectively in the concentration range of $0.25 \mathrm{nmol} / 1-25 \mathrm{nmol} / \mathrm{l}$ ATP. The influence of the amount of the luciferin-luciferase reagent on the light production was studied at a fixed $5 \mathrm{nmol} / \mathrm{l}$ ATP and $0.7 \mathrm{~g} / 1$ detergent concentration. At $10 \mathrm{nmol} / 1$ ATP, the effect of the detergents on the bioluminescent intensity was investigated. The time dependence of the light signal was also analysed in the absence and in the presence of $0.8 \mathrm{~g} / 1$ nonionic detergent at an ATP concentration comparable to that released from the red cells.

Sample handling and monitoring of intracellular ATP release

The nonionic detergent-induced ATP release was analysed on freshly drawn and on preincubated erythrocytes. The EDTAtreated blood samples were first prediluted 1000 fold with 0.15 mol/1 $\mathrm{NaCl}$ and the ATP release kinetics monitored immediately. The mobilization of intracellular ATP was also followed after incubation of the same prediluted samples at $37^{\circ} \mathrm{C}$ for 4 hours. In the control experiments, $50 \mu$ l of the prediluted blood sample was pipetted into $1.2 \mathrm{ml}$ of reagent mixture (without detergent), and the light signal was measured for 1024 seconds, while quickly rotating the cuvette backwards and forwards. For monitoring of the detergent-induced ATP release from the red cells, $50 \mu \mathrm{l}$ of prediluted blood was pipetted into $1.1 \mathrm{ml}$ of the reagent mixture and photon counting was started as above. After 1 minute, $0.1 \mathrm{ml}$ of $10 \mathrm{~g} / 1$ Brij 58 or Triton X 100 was injected quickly into the cuvette (the end concentration of the detergents was $0.8 \mathrm{~g} / \mathrm{l}$ ). Reproducibility of the release curves was examined using the same blood sample in 5-8 consecutive experiments. The time intervals needed to reach half of the maximal ATP release (50\% ATP release) and the maximal release were also analysed for both detergents in parallel measurements.

Long term ATP release was monitored with the LB 9505 instrument in the same way, but without continuous rotation of the cuvette.

\section{Quantitative analysis of ATP release}

For the estimation of the ATP released from the detergenttreated cells we used the additive ATP standard technique (9), with the modification that instead of running duplicate samples a known amount of ATP was added to the samples in a negligibly small volume $(20 \mu \mathrm{l})$. In the case of the Triton $X 100$ treated samples, the ATP standards were added after a 1-2 minute measuring period, while for the Brij 58-treated samples standardization was performed when the ATP release was maximal. The end concentration of the standards in the cuvette was $19.4 \mathrm{nmol} / \mathrm{l}$. Serial quantitative analysis of the Brij 58-induced ATP release was done using the LB 9505 six channel instrument working in the automatic time axis mode. Standards were added at the maximum of the bioluminescence signal and 3 consecutive readings were averaged.

\section{Quantitation of ATP by acid extraction}

The ATP content of the red cells was also determined by perchloric acid extraction (10) with the following modification. The anticoagulated blood samples (freshly drawn or incubated at $37^{\circ} \mathrm{C}$ for 4 hours) were first diluted 100 fold with $0.15 \mathrm{~mol} / \mathrm{l}$ $\mathrm{NaCl}$. Diluted blood $(0.5 \mathrm{ml})$ was mixed with $0.5 \mathrm{ml}$ of $1 \mathrm{~mol} / \mathrm{l}$ perchloric acid then centrifuged at $3000 \mathrm{~g}$ for 8 minutes. Supernatant $(0.1 \mathrm{ml})$ was mixed with $0.5 \mathrm{ml}$ of $0.1 \mathrm{~mol} / 1 \mathrm{Tris} /$ acetate, $20 \mathrm{mmol} / 1 \mathrm{EDTA} \cdot \mathrm{Na}_{2}, \mathrm{pH} 7.7$ (11). For the measurement of ATP, $50 \mu \mathrm{l}$ of the Tris/EDTA neutralized extract was pipetted into $1.1 \mathrm{ml}$ of ATP reagent mixture. After a 1-2 minute measuring period, $20 \mu \mathrm{l}$ of ATP istandard solution was added (end concentration of standard in the cuvette was 21.1 $\mathrm{nmol} / \mathrm{l}$ ) and the bioluminescence measured. 


\section{Results}

\section{ATP standard curves}

The presence of $0.8 \mathrm{~g} / 1$ Triton X 100 or Brij 58 in the reagent mixture did not alter the ATP-dependent light production significantly (fig. 1). The Brij 58 detergent caused an unexpected slight increase $(\sim 20 \%)$ while Triton X 100 treatment caused a moderate decrease $(\sim 30 \%)$ in the light emission of the firefly system.

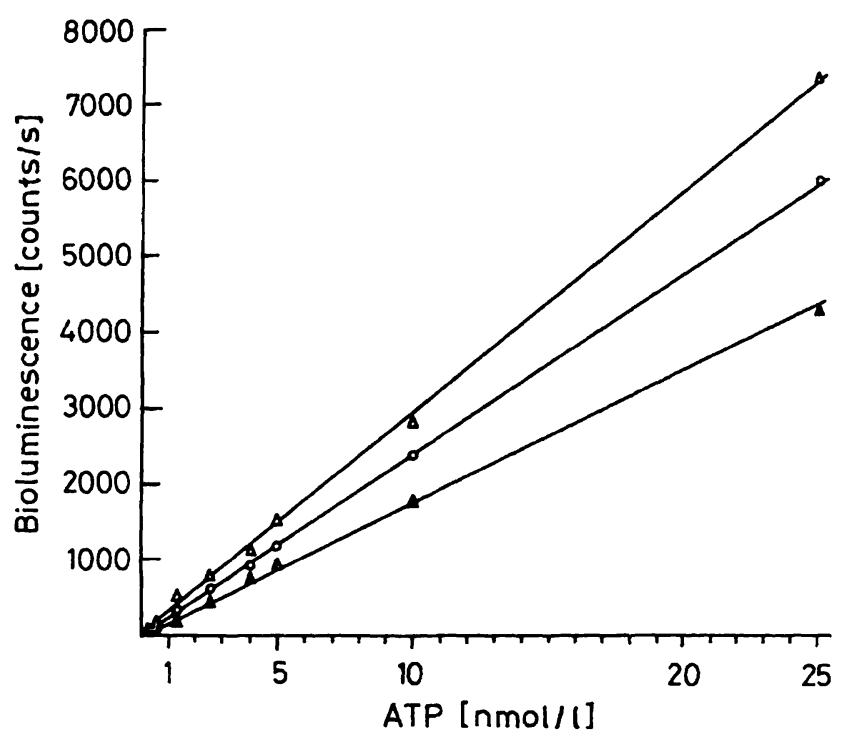

Fig. 1. Effect of nonionic detergents on the light emitting reaction. ATP standard curves in the absence of detergent $(0)$ and in the presence of $0.8 \mathrm{~g} / 1$ Triton X $100(\Delta)$ or in the presence of $0.8 \mathrm{~g} / 1$ Brij $58(\Delta)$. The equations of the computed regression lines and the coefficients of correlation (r) are as follows:

$y=237 x+18, r=0.999$ (no detergent),

$y=167 x+73, r=0.999$ (Triton X 100),

$y=290 x+26, r=0.999$ (Brij 58).

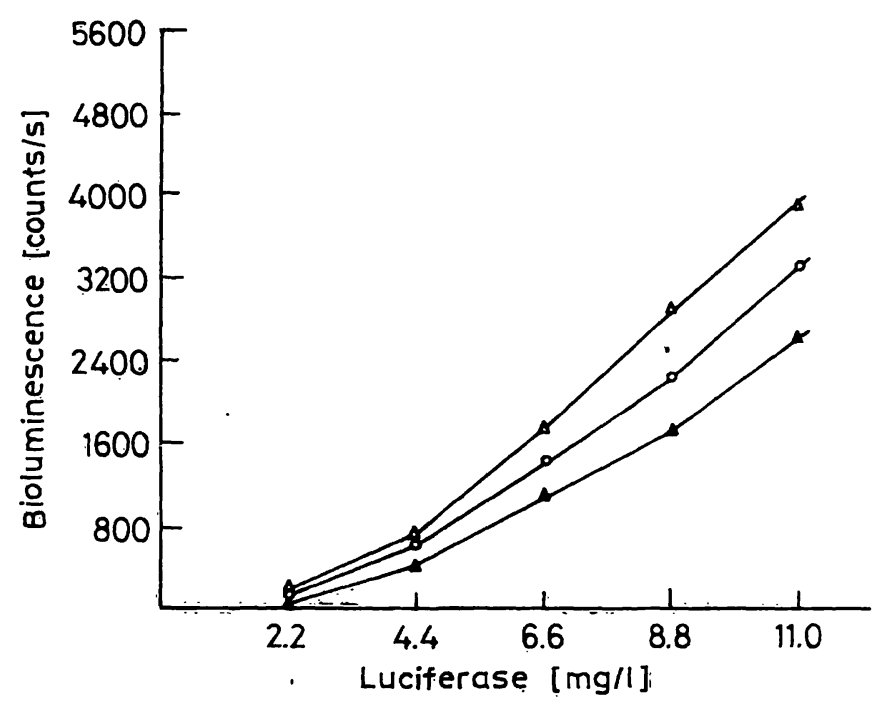

Fig. 2. Effect of luciferase concentrations on the light emission of the firefly system. $5 \mathrm{nmol} / \mathrm{l}$ ATP standard solution in the absence of detergent $(0)$ and in the presence of 0.7 $\mathrm{g} / 1$ Triton X $100(\Delta)$ or in the presence of $0.7 \mathrm{~g} / \mathrm{l} \mathrm{Brij}$ $58(\Delta)$.

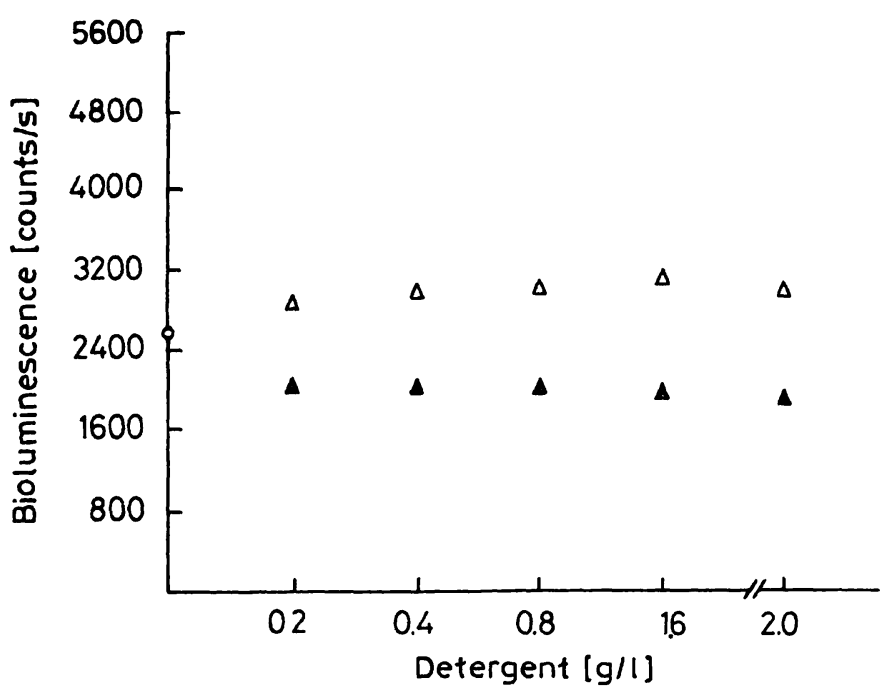

Fig. 3. Effect of nonionic detergent concentration on the bioluminescence intensity. $10 \mathrm{nmol} / 1$ ATP standard solution in the absence of detergent $(0)$ and in the presence of Triton X $100(\Delta)$ or in the presence of Brij $58(\Delta)$.

In each case the linearity of the method was completely preserved, at least within a $0.25 \mathrm{nmol} / 1-25$ nmol/l concentration range $\left(\mathrm{r}^{2} \sim 1\right)$. With increasing amounts of the luciferase $(2.2-11 \mathrm{mg} / \mathrm{l})$ both the positive effect of Brij 58 and the negative effect of Triton X 100 were maintained (fig. 2). Variation of the detergent concentration $(0.2 \mathrm{~g} / \mathrm{l}-2.0 \mathrm{~g} / \mathrm{l})$ in the samples at the $10 \mathrm{nmol} / \mathrm{l}$ ATP concentration, caused no detectable change in the intensity of the emitted light (fig. 3). At $16 \mathrm{nmol} / \mathrm{l} \mathrm{ATP}$ and in the presence of $0.8 \mathrm{~g} / 1$ Triton $X 100$ or Brij 58 the decay of the bioluminescence intensity with time was examined. We observed a low and steady decrease of the emitted light during the nearly 20 minute detection period either in the absence, or in the presence of nonionic detergents (fig. 4). In both cases the decay of luminescence intensity did not exceed $10 \%$ of the initial value.

Photon counts obtained for ATP standard solutions in the presence of haemoglobin indicated no measurable loss of the emitted light due to haemoglobin, at least in the concentration range used in the ATP release experiments (data not shown).

\section{Intracellular ATP release kinetics}

In the absence of nonionic detergents, the red cells tolerated the surrounding medium (i.e. the reagent mixture) and no significant release of intracellular ATP could be detected (fig. 5 a). On the other hand, the presence of $0.8 \mathrm{~g} / 1$ Triton X 100 or Brij 58 caused the mobilization of ATP from the cells. However, 


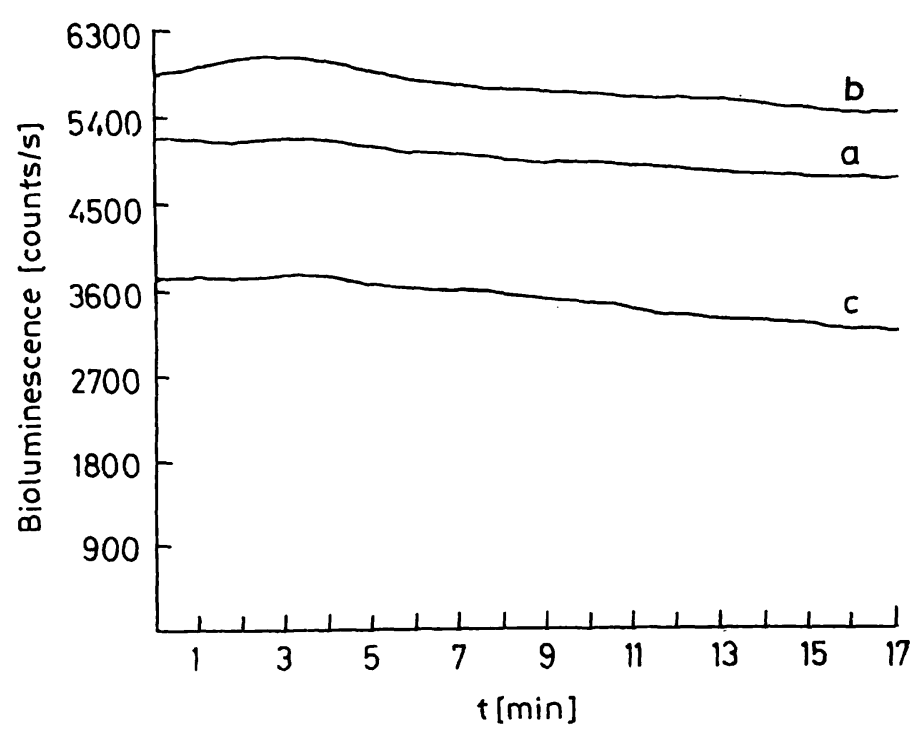

Fig. 4. Effect of nonionic detergents on the time dependence of the light emitting reaction. $16 \mathrm{nmol} / \mathrm{l}$ ATP standard solution in the absence of detergent (a) and in the presence of $0.8 \mathrm{~g} / \mathrm{l}$ Triton $\mathrm{X} 100$ (c) or in the presence of $0.8 \mathrm{~g} / \mathrm{l}^{\prime}$ Brij 58 (b).

there was a striking difference in the ATP release kinetics between Triton X 100 and Brij 58. Triton X 100 treatment resulted in an almost immediate and maximal release of ATP while the Brij 58-induced mobilization of ATP was much slower. On figures $5 \mathrm{c}$ and $b$, respectively, representative release curves for the two detergents are shown. The Brij 58-induced mobilization of ATP began after an approximatively 1 minute lag phase and maximal response was detected between 17 and 55 minutes. Although there was a wide variation in the time periods needed for the maximal ATP release among the individual blood samples, the reproducibility of the release curves was still very good. The time required to reach $50 \%$ of the maximal ATP mobilization for the sample indicated in figure $5 \mathrm{~b}$ was found to be $186 \pm 7$ seconds $(\mathrm{n}=5$, coefficient of variation $\mathrm{CV}=3.8 \%)$. The $50 \%$ ATP release for the Triton X 100-treated blood samples was complete within $1-2$ seconds. Long term

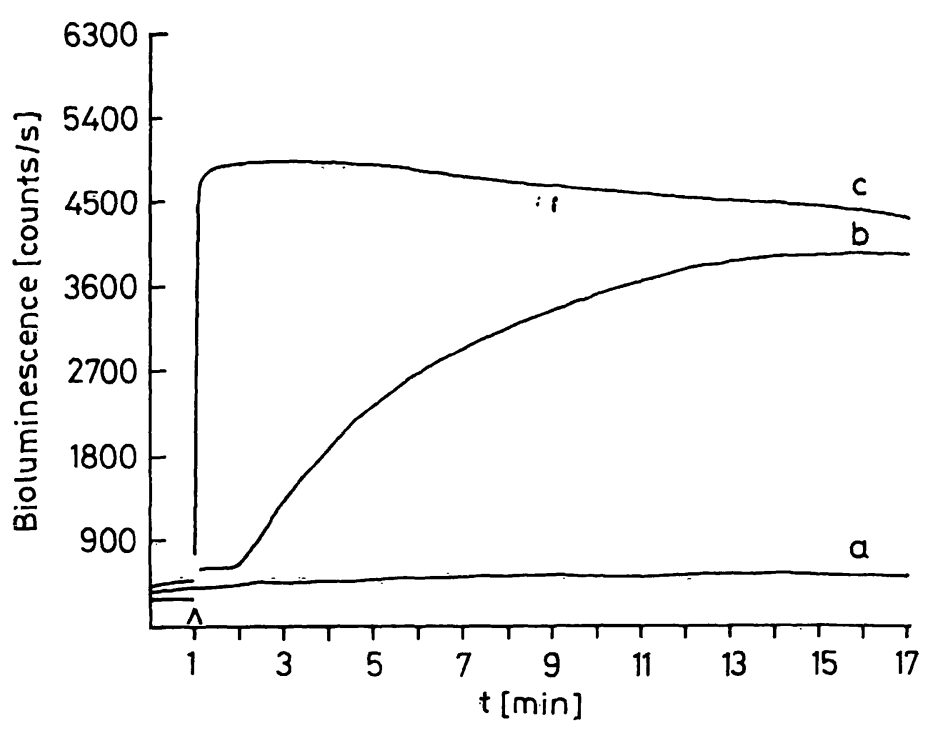

Fig. 5. Nonionic detergent-induced ATP release kinetics in human erythrocytes. Cells were incubated in the absence of detergent (a) and in the presence of $0.8 \mathrm{~g} / 1$ Triton $X$ 100 (c) or in the presence of $0.8 \mathrm{~g} / 1$ Brij 58 (b).

The arrow indicates the time of addition of the detergents to the samples.

monitoring of the Brij 58-induced mobilization of intracellular ATP revealed that in several cases the release curves were biphasic i.e. after a plateau we detected an additional ATP mobilization reaching a new equilibrium (to be published).

\section{The amount of released ATP}

The nonionic detergent-induced release of intracellular ATP was quantitated by the use of additive standards, and the results were also compared with the ATP values obtained after perchloric acid extraction of the same blood samples. For Brij treatment the time intervals needed to reach the maximal ATP mobilization were also determined. Our results showed (see tab. 1) that the measurement of the released ATP after Triton X 100 treatment gave a fairly good estimate of the perchloric acid extractable (total) ATP content of the erythrocytes. The accuracy of the

Tab. 1. Analysis of released ATP and the time intervals required to reach maximal ATP release $\left(T_{\max }\right)$ in the presence of nonionic detergents.

Standard deviations are indicated as $\pm 2 \mathrm{SD}$.

\begin{tabular}{|c|c|c|c|c|c|}
\hline \multirow[t]{2}{*}{ Blood samples } & \multirow{2}{*}{$\begin{array}{l}\text { Perchloric acid } \\
\text { ATP content } \\
\text { (mmol/l red cell) }\end{array}$} & \multicolumn{2}{|l|}{$\begin{array}{l}\text { Treatment } \\
\text { Triton X } 100\end{array}$} & \multicolumn{2}{|l|}{ Brij 58} \\
\hline & & $\begin{array}{l}\text { ATP content } \\
\text { (mmol/l red cell) }\end{array}$ & $\begin{array}{l}T_{\max } \\
\text { (seconds) }\end{array}$ & $\begin{array}{l}\text { ATP content } \\
(\mathrm{mmol} / \mathrm{l} \mathrm{red} \text { cell) }\end{array}$ & $\begin{array}{l}\mathrm{T}_{\max } \\
\text { (mấinutes) }\end{array}$ \\
\hline Freshly drawn & $\begin{array}{l}1.71 \pm 0.30 \\
(n=32)\end{array}$ & $\begin{array}{l}1.72 \pm 0.30 \\
(\mathrm{n}=32)\end{array}$ & $\begin{array}{l}<3 \\
(n=12)\end{array}$ & $\begin{array}{l}1.32 \pm 0.32 \\
(n=12)\end{array}$ & $\begin{array}{l}36.5 \pm 9.2 \\
(n=12)\end{array}$ \\
\hline $\begin{array}{l}\text { Preincubated } \\
\left(37^{\circ} \mathrm{C}, 4 \text { hours }\right)\end{array}$ & - & $\begin{array}{l}0.73 \pm 0.17 \\
(n=12)\end{array}$ & $\begin{array}{l}<3 \\
(n=12)\end{array}$ & $\begin{array}{l}0.59 \pm 0.19 \\
(n=12)\end{array}$ & $\begin{array}{l}22.9 \pm 4.1 \\
(n=12)\end{array}$ \\
\hline
\end{tabular}


method was demonstrated by comparison with the well established perchloric acid extraction. Statistical analysis revealed no significant difference $(p<0.2)$ between the two methods, the equation of the computed regression line was $y=0.974 x+0.059$ with a coefficient of correlation $r=0.933(n=32)$.

The reproducibility of the Triton method was acceptable with a within-run imprecision of $\mathrm{CV}=3.8 \%$ $(n=17)$. On the other hand, Brij 58 treatment of the red cells always mobilized a lesser amount of ATP for both the freshly drawn and preincubated samples than did the Triton X 100 treatment of the same cells. Incubation of the prediluted blood samples at $37^{\circ} \mathrm{C}$ for 4 hours not only decreased the total ATP content of the erythrocytes but also shortened the time intervals needed for maximal ATP release in the presence of Brij 58 (tab. 1).

\section{Discussion}

Previous studies showed that the firefly bioluminescence system was suitable for the continuous monitoring of the formation or breakdown of ATP in different biochemical reactions, and in the presence of isolated cellular organelles $(12-15)$. Recently, the thrombin-induced release kinetics of ATP from human platelets was followed by the luciferin-luciferase method (16). Unfortunately, the method used for the permeabilization of platelets is not applicable directly to other mammalian cells, because they cannot be permeabilized by treatment with thrombin, ADP, collagen, etc.

The main achievement of the present work is the use of Triton X 100 (17) and Brij 58 (18) nonionic detergents as permeabilizing agents, and the adaptation of the firefly bioluminescence method for the direct monitoring of the ATP release from human red cells in the presence of these detergents. Our analyses, performed first on aqueous ATP standard solutions, either in the absence, or in the presence of Triton $\mathrm{X}$ 100 and Brij 58 respectively, revealed no significant changes in the light emission of the luciferin-luciferase system. However, a quenching effect of Triton X 100 $(\sim 30 \%)$ and a slight enhancing effect of Brij 58 $(\sim 20 \%)$ was observed within a wide ATP and luciferase concentration range (see figs. $1,2,4)$. The quenching and enhancing effects were also independent of the detergent content of the samples $(0.2 \mathrm{~g} / 1-$ $2.0 \mathrm{~g} / 1$, see fig. 3). The mechanism of the enhanced light emission in the presence of Brij 58 is not completely understood. The spontaneous luminescence decay was negligible (fig. 4), indicating that product inhibition (19) or other systematic error did not distort our ATP release data.

In the ATP release experiments approximately $2 \times 10^{5}$ red cells per sample were treated with nonionic detergents. The mobilization of ATP was dramatically rapid in the case of Triton X 100 (within seconds) while for Brij 58 the required time for maximal release was found to be $18-55$ minutes. In spite of the great divergence in the time needed for the maximal mobilization of ATP, the Brij-induced ATP release curves were reproducible $(\mathrm{CV}=3.8 \%$ for $50 \%$ ATP release). It seems that Triton X 100 treatment resulted in the mobilization of the total ATP content of the red cell (when compared with the accepted perchloric acid method), while the amount of the detected ATP at maximal release in the presence of Brij 58 was only about $65-85 \%$ of the total cellular ATP (tab. 1). The mechanism of the incomplete ATP release in the presence of Brij 58 has not been clarified. Our quantitative ATP data for freshly drawn erythrocytes were comparable to those of the corresponding literature $(20-22)$.

Triton X 100 and Brij 58 are known to have almost the same lipolytic effect but differ at a great extent in the rate of the mobilization of intracellular proteins (6). The Brij 58-induced much slower protein release was observed in different cell types and even intracellular $\mathrm{K}^{+}$was found to express a retarded diffusion from the Brij 58-permeabilized cells, indicating the existence of a close contact between $\mathrm{K}^{+}$and the intracellular proteins $(7,8)$. In our experiments, the detected very rapid ATP release kinetics of the Triton $\mathrm{X} 100$-, and the much slower ATP mobilization rate of the Brij 58-treated cells were in good agreement with the nonionic detergent-induced protein and $\mathrm{K}^{+}$ mobilization found in other cells (8).

These data strongly suggest that a significant amount of the intracellular ATP is associated with the proteins of the living cell. This hypothesis gets further support by our observation that incubation of the erythrocytes in nutrient free medium $(0.15 \mathrm{~mol} / \mathrm{l} \mathrm{NaCl})$ not only decreased the total amount of ATP in the cells but also shortened the time intervals required to reach the maximal ATP release in the presence of Brij 58 (tab. 1). In other words, a decrease in the amount of red cell ATP alters the protein binding of the intracellular ATP.

On the basis of our results, we conclude that the present method is a valuable tool for gathering data on the distribution and compartmentation of ATP in the living cells in normal as well as pathological conditions. 


\section{References}

1. Strange, R. E., Wade, H. E. \& Dark, F. A. (1963) Nature 199, 55-57.

2. Beutler, E. \& Baluda, M. C. (1964) Blood 23, 688-697.

3. Ellis, R. J. \& Gardner, C. (1980) Anal. Biochem. 105, 354360.

4. Lust, W. D., Feussner, G. K., Barbehehn, E. K. \& Passoneau, J. V. (1981) Anal. Biochem. 110, 258-261.

5. Lundin, A. \& Thore, A. (1975) Appl. Microbiol. 30, 713721.

6. Schliwa, M., van Blerkom, J. \& Porter, K. R. (1981) Proc. Natl. Acad. Sci. USA 78, 4329-4333.

7. Kellermayer, M., Rouse, D., Gyorkey, F. \& Hazlewood, C. F. (1984) Physiol. Chem. Phys. Med. NMR 16, 503-511.

8. Kellermayer, M., Ludany, A., Jobst, K., Szucs, Gy., Trombitas, K. \& Hazlewood, C. F. (1986) Proc. Natl. Acad. Sci. USA 83, $1011-1015$.

9. Turner, G. K. (1985) In: Bioluminescence and Chemiluminescence: Instruments and Applications Vol. I. (Van Dyke, K., ed.), p. 56, CRC Press, Boca Raton, Florida.

10. Wiener, S., Wiener, R., Urivetzky, M. \& Meilman, E. (1974) Anal. Biochem. 59, 489-500.
11. Jabs, C. M., Ferrell, W. J. \& Robb, H. J. (1977) Clin. Chem. 23, 2254-2257.

12. Lundin, A., Rickardsson, A. \& Thore, A. (1976) Anal. Biochem. 75, $611-620$.

13. Lundin, A., Thore, A. \& Baltscheffsky, M. (1977) FEBS Lett. 79, 73-76.

14. Lemasters, J. J. \& Hackenbrock, C. R. (1973) Biochem. Biophys. Res. Commun. 55, 1262-1270.

15. Lemasters, J. J. \& Hackenbrock, C. R. (1976) Eur. J. Biochem. 67, 1-10.

16. Detwiler, T. C. \& Feinman, R. D. (1973) Biochemistry 12, 2462-2468.

17. Miozzari, G. F., Niederberger, P. \& Hütter, R. (1978) Anal. Biochem. 90, 220-233.

18. Ganesan, A. T. (1971) Proc. Nat. Acad. Sci. USA 68, 1296-1300.

19. Deluca, M. A. \& McElroy, W. D. (1974) Biochemistry 13, $921-925$.

20. Féo, C. J. \& Leblond, P. F. (1974) Blood 44, 639-647.

21. Rubinstein, D. \& Warrendorf, E. (1975) Can. J. Biochem. $53,671-678$.

22. Beutler, B. \& Baluda, M. C. (1964) Blood 23, 688-697.

Dr. Tamás Köszegi

Department of Clinical Chemistry

Ifjuság u. 13

H-7624 Pécs 